Position Paper

\title{
Biologics for severe uncontrolled chronic rhinosinusitis with nasal polyps: a change management approach. Consensus of the Joint Committee of Italian Society of Otorhinolaryngology on biologics in rhinology
}

\author{
Biologici nel trattamento della poliposi naso-sinusale severa non controllata: \\ cambiamento nelle strategie terapeutiche. \\ Consensus dei membri della Commissione SIO sui farmaci biologici in rinologia
}

\begin{abstract}
Eugenio De Corso ${ }^{1}$, Gianluca Bellocchi², Michele De Benedetto ${ }^{3}$,
Nicola Lombardo ${ }^{4}$, Alberto Macchi ${ }^{5}$, Luca Malvezzi ${ }^{6}$, Gaetano Motta ${ }^{7}$,

Fabio Pagella ${ }^{8}$, Claudio Vicini ${ }^{9}$, Desiderio Passali ${ }^{10}$

Fondazione Policlinico Universitario A. Gemelli IRCCS, Head and Neck Surgery Otorhinolaryngology, Rome, Italy; ${ }^{2}$ ENT Department, San Camillo-Forlanini Hospital, Roma, Italy; ${ }^{3}$ ENT Unit, Vito Fazzi Hospital, ASL Lecce, Italy; ${ }^{4}$ ENT Unit Department of Medical and Surgical Sciences, University Magna Græcia Catanzaro, Italy; ${ }^{5}$ ENT University of Insubria, Varese, ASST Settelaghi, Italy; ${ }^{6}$ IRCCS Humanitas Research Hospital, Department of Otorhinolaryngology and Head and Neck Surgery, Rozzano, Milan, Italy; 7 Otorhinolaryngology-Head and Neck Surgery, University of Campania L. Vanvitelli, Napoli, Italy; ${ }^{8}$ ENT Department, I.R.C.C.S. Policlinico San MatteoUniversity of Pavia, Italy; ${ }^{9}$ Department of Head-Neck Surgery, Otolaryngology, Head-Neck and Oral Surgery Unit, Morgagni Pierantoni Hospital, Forli, Italy; ${ }^{10}$ IFOS Former President and Executive Board member, Rome, Italy
\end{abstract}

\section{SUMMARY}

Chronic rhinosinusitis with nasal polyps (CRSwNP) is a heterogeneous inflammatory condition of nasal mucosa and paranasal sinuses, predominantly mediated by type 2 inflammation and often associated with comorbid asthma and/or Exacerbated Respiratory Disease (N-ERD). The standard of care involves local and systemic corticosteroids and/or sinonasal surgery, although these options may be associated with recurrences and patients may require revision surgery. Difficult-to-treat patients, in fact, have a more severe disease requiring high systemic corticosteroid use and/or multiple sinonasal surgeries. Literature data suggests that biologic agents targeting specific key effectors of type 2 inflammation may offer supplemental therapy for patients with severe and uncontrolled CRSwNP, leading to significant improvement in several outcomes. For these reasons, over the years the endotyping of the disease has become increasingly important. Herein, we provide not only an update on the existing studies about the most promising biologics in CRSwNP, but also critical discussion on controversies about the use of biologics in severe uncontrolled CRSwNP. We finally provide consensus on strategic issues gathered among experts of the Joint Committee of Italian Society of Otorhinolaryngology on biologics in order to offer the best care for difficult to treat patients.

KEY WORDS: type 2 inflammation, chronic rhinosinusitis with nasal polyps, biologics, endoscopic sinus surgery, endotyping

\section{RIASSUNTO}

La rinosinusite cronica con poliposi naso sinusale è una condizione infiammatoria cronica della mucosa naso sinusale, sostenuta prevalentemente da infiammazione di tipo 2 che si associa frequentemente a comorbidità come asma e intolleranza ai FANS. I recenti studi
Extract from the workshops of the Joint Committee of Italian Society of Otorhinolaryngology on biologics in rhinology in 2020.

Received: April 14, 2021

Accepted: June 16, 2021

Pubished online: July 23, 2021

\section{Correspondence}

Eugenio De Corso

Otorhinolaryngology - Head and Neck Surgery, Rhinology Unit, “A. Gemelli” Hospital Foundation IRCCS, Catholic University of the Sacred Heart largo A. Gemelli 8, 00168 Rome, Italy

E-mail: eugenio.decorso@policlinicogemelli.it

\begin{abstract}
How to cite this article: De Corso E, Bellocchi $\mathrm{G}$, De Benedetto M, et al. Biologics for severe uncontrolled chronic rhinosinusitis with nasal polyps: a change management approach. Consensus of the Joint Committee of Italian Society of Otorhinolaryngology on biologics in rhinology. Acta Otorhinolaryngol Ital 2022;42:1-16. https:// doi.org/10.14639/0392-100X-N1614
\end{abstract}

() Società Italiana di Otorinolaringoiatria e Chirurgia Cervico-Facciale

\section{(c) (1) $(2)$}

This is an open access article distributed in accordance with the CC-BY-NC-ND (Creative Commons Attribution-NonCommercial-NoDerivatives 4.0 International) license. The article can be used by giving appropriate credit and mentioning the license, but only for non-commercial purposes and only in the original version. For further information: https:// creativecommons.org/licenses/by-nc-nd/4.0/deed.en 
sull'endotyping di malattia hanno rivelato il ruolo cruciale delle citochine dell'infiammazione di tipo 2 nella patogenesi delle forme più severe. L'approccio terapeutico negli ultimi anni si è basato sull'uso di corticosteroidi locali/sistemici e chirurgia endoscopica naso-sinusale. I pazienti con forme più severe, tuttavia, richiedono impiego di alte dosi di corticosteroidi sistemici e ripetuti interventi chirurgici. I dati della letteratura hanno confermato che i nuovi farmaci biologici, specifici per le citochine dell'infiammazione di tipo 2, possono rappresentare un approccio supplementare offrendo un significativo miglioramento clinico nei pazienti affetti da poliposi naso sinusale severa e non controllata. In questo lavoro riportiamo non solo i risultati di una revisione sistematica della letteratura sulle attuali evidenze dei più promettenti farmaci biologici in poliposi naso-sinusale severa non controllata, ma anche i risultati di una consensus su alcuni degli argomenti più dibattuti estratti dai verbali delle riunioni dei membri della Commissione della Società Italiana di Otorinolaringoiatria sui farmaci biologici in rinologia durante il 2020.

PAROLE CHIAVE: infiammazione di tipo 2, rinosinusite cronica con poliposi nasale, biologics, chirurgia endoscopica nasosinusale, endotyping

\section{Introduction}

Chronic rhinosinusitis with nasal polyposis (CRSwNP) is a complex inflammatory disorder including multiple phenotypes. It is a debilitating disease that has a substantial impact on the patient's quality of life with significant healthcare-related costs. Over the years, management strategies have been focused mainly on symptom relief including intranasal corticosteroid (INCS), saline irrigations and a brief courses of systemic corticosteroids (SCS) with or without antibiotics to manage acute exacerbations that may be associated with significant quantitative changes in inflammatory biomarkers ${ }^{1-4}$. Optional treatments include macrolide, anti-leukotrienes, anti-histamine and aspirin desensitisation only for patients with NSAIDs Exacerbated Respiratory Disease (N-ERD). If maximal medical therapy does not lead to adequate control of symptoms, endoscopic sinus surgery (ESS) is considered to remove inflammatory tissue alleviating nasal obstruction and expediting delivery of topical therapies. Surgery is not curative but is crucial in improving access for future topical medical therapy ${ }^{5}$.

Unfortunately, a significant percentage of patients do not find relief from current standard of care medications and surgery having residual symptoms or recurrence of polyposis even cycles of systemic corticosteroids and/or surgery. "Difficult-totreat" patients are considered as those in whom an acceptable level of control is not achieved despite appropriate medical and surgical treatment. For these patients, the only chance in recent years was to repeat multiple ESS with an increasingly high risk of perioperative complications and a progressively shorter time of symptom control between surgeries ${ }^{6,7}$. The success in targeting specific immunologic mediators in asthma with biologics has led to an interest in the use of a similar therapeutic approach for $\mathrm{CRSwNP}^{8}$. Several trials ${ }^{9}$ have shown subjective and objective improvements in patients with CRSwNP with or without asthma as well as a good safety profile. For this reason, biologic agents have been proposed as an adjunct treatment for CRSwNP patients and in the next months, the therapeutic opportunity may change quickly because several monoclonal antibodies (MAbs) will be available within a short time in many countries for uncontrolled severe CRSwNP.
As some biologics have received regulatory approval in Italy, the Joint Committee of Italian Society of Otorhinolaryngology on biologics in rhinology became interested in how to incorporate these new agents into the treatment paradigm for CRSwNP. In this report we summarise the substantial literature evidence about the most promising biologics in CRSwNP presenting a consensus on the most critical issues that emerged from the workshops of the commission in 2020. We aimed to provide consensus on strategic issues to offer the best care for patients with severe uncontrolled CRSwNP. It is hoped that this report will be used by researchers and clinicians who will address the incorporation of these new therapeutic modalities into the CRSwNP treatment algorithm.

\section{Materials and methods}

We used the RAND indication for standard Delphi methodology with a multi-step process. Specific statements were formulated basing on an extensive review of existing literature about the use of biologics in CRSwNP. Manuscript were screened primarily by Ovid Medline and EMBASE and from other sources (PubMed Central, Cochrane review, Web of Science, and Google Scholar). Our expert panel undertook a modified 2-round Delphi process and members were asked to independently vote on statements, which were formulated based on strategic discussion during 2020. We used a 4-point Likert scale ('strongly agree', 'agree', 'disagree', 'strongly disagree'). Free text comments were encouraged if greater context was required or if the statements were ambiguous. Consensus was defined as $>70 \%$ of participants agreeing/ strongly agreeing. The document was written and submitted for review and approval to all the members of the committee. All changes made were discussed and refined until unanimous approval was obtained. Statements receiving consensus are summarised at the end of each paragraph.

\section{Results and discussion}

\section{Management based on phenotyping and endotyping of the disease}

Chronic rhinosinusitis (CRS) comprises a spectrum of 
conditions with distinct clinical presentations and pathogenic mechanisms ${ }^{1,10,11}$. For years it has been adopted clinical dichotomisation of CRS without NP (CRSsNP) and CRSwNP assuming that it was determined by predominantly T-helper 1 cells in the former and T-helper 2 cells in the latter. However, further research demonstrated that immunologic profile is much more complex, demonstrating that there is some overlap and endotypes may coexist in the same patient. In fact, non-eosinophilic inflammation dominated by Th1/Th17 pathways may be associated with CRSwNP and CRSsNP patients may express a Type 2 cytokine profile ${ }^{12-15}$. Because studies on endotyping provided full insight into the underlying cellular and molecular inflammatory mechanisms associated with CRS ${ }^{16}$, the EPOS 2020 group ${ }^{1}$ came into the decision to change the management approach to CRS. The authors recognised the importance to move away from differentiating management basing on phenotypical classification between CRSsNP and CRSwNP towards a new classification based on the disease being localised (often unilateral) or diffuse (always bilateral). Both these groups are further divided basing the endotype into type 2 or non-type 2 disease. In case of more endotypes coexisting in the same patient, the authors suggested to identify the dominant one in order to establish the best personalised therapeutic approach.

Approximately $80 \%$ of diffuse CRS in Western countries are characterised by a dominant Type 2 response driven mainly by key Type 2 cytokines (IL4, IL5, IL13 etc) and circulating/local IgE, with eosinophilia as a typical signature ${ }^{16-18}$. Currently, both an allergic (IgE-mediated) and non-allergic pathway are understood to play a role in the pathophysiology of the underlying eosinophilia, representing the ideal immune profile of severe CRSwNP potentially candidates for biologics. For this reason, recent position papers ${ }^{1,19}$ suggested to provide confirmatory evidence of Type 2 inflammation in these patients using systemic eosinophil and IgE count. It has also demonstrated that the amount of local eosinophilic infiltration and the overall intensity of the inflammatory response are closely related to the prognosis and severity of disease ${ }^{20}$. For this reason, development of institutional protocols for sampling, storing and processing sino-nasal mucosa samples, sometimes in close collaboration with histopathologists is increasing ${ }^{21}$. Actually, authors discuss on the best procedure to define local inflammation and the most common used techniques include: nasal biopsy, nasal brushing or scraping (nasal cytology), nasal lavage fluid and nasal suctioning of secretions ${ }^{22-26}$. Authors ${ }^{27-29}$ have suggested that diagnosis of eosinophilic CRS requires quantification of the numbers of eosinophils, i.e. number/high powered field (hpf), which may vary in the literature $(8-12 / \mathrm{hpf})$ and which should be achieved by analysing at least three of the most dense collections of eosinophils (very rich fields) in the samples counted at hpf $(\sim 400 x)$. The EPOS steering group ${ }^{1}$ specified that the minimal cut-off to achieve evidence of Type 2 inflammation on tissue samples was eosinophils $>10 / \mathrm{hpf}$. The cut-offs for the other procedures had not be established and specific studies are required to determine it. Other biomarkers used at the moment to define type 2 disease are blood eosinophilia, IgE levels and, in some specialised centers, periostin. EPOS group suggests as specific cut offs for this biomarker: $>250 /$ microliter for blood eosinophilia and $>100 \mathrm{kU} / \mathrm{l}$ for total IgE. Other biomarkers are currently under investigation and may provide further guidance in the future.

The combination of phenotyping (responsiveness to different treatments, including systemic or intranasal corticosteroids, surgical interventions, comorbid asthma, N-ERD, etc.) and endotyping [blood/local eosinophils or neutrophils, THcell populations, levels of cytokines (IL-4, IL-5, or IL-13, etc.), IgE either in blood or tissue, anti-staphylococcal IgE, periostin and other future potential biomarkers] are at the moment the best way to predict the likely natural course of disease and prognosis in terms of disease control after surgery. Based on this concept, many authors ${ }^{21,28,30-34}$ have tried to identify the best way to predict the natural history of the disease, facilitating counseling the patient on the expected outcome of the surgery and helping to establish the best postoperative medical management that can offer the best chance to control patient's symptoms. Finally, identification of endotypes is essential for individualisation of therapy.

\section{Adequate endotyping and phenotyping of the disease should be refined in an additional work-up in all severe uncontrolled CRSwNP patients.}

\section{ENT physicians involved in prescription of biologics in rhinology centers should standardise the diagnostic work-up for severe uncontrolled CRSwNP strengthening multidisciplinary cooperation to define endotype of the disease and eligibility for biologics.}

Rhinologic centers should develop institutional protocols for determination of type 2 inflammation associated with severe uncontrolled CRSwNP.

Clinical predictors of treatment outcomes are useful to foresee the likely natural course of disease and facilitate counseling of patients on expected outcomes of standard of care treatments.

The new age of biologics in CRS: from scientific evidence to approval of new treatment options

Monoclonal antibodies have been demonstrated to be very useful in the management of chronic eosinophilic diseases 
such as asthma and atopic dermatitis; the experience in these fields encouraged researchers to investigate efficacy of these drugs in CRSwNP. Proof-of- concept studies ${ }^{35-40}$ were performed mainly in patients with severe asthma and nasal polyps, generating promising results and building upon successful phase 3 studies ${ }^{41}$.

The pathophysiology of CRSwNP includes eosinophilia, T-helper cell 2 cytokines and $\operatorname{IgE}$ formation, and for this reason three main strategies may be undertaken with monoclonal antibodies: anti-IL-4/IL-13 signaling (dupilumab), anti-IL-5 pathways (mepolizumab, benralizumab) and anti-IgE antibodies (omalizumab). In Table I we summarise mechanism of action, possible side effects, dose, and administration modalities of most promising biologics in the treatment of CRSwNP. Furthermore, we reviewed literature evidence about their significative steps in the approval process (Tab. II).

\section{Anti-IL-4/IL-13: Dupilumab}

Dupilumab is a fully human monoclonal antibody targeting the $\alpha$-chain subunit of IL- 4 receptors (Type 1 and type 2 IL-4R $\alpha$ ) and inhibiting IL-4/IL-13 signaling ${ }^{35}$. Literature data ${ }^{42-44}$ have demonstrated that the dual inhibition of IL-4 and IL-13 signaling may represent an important strategy for the treatment of type 2 CRSwNP. Bachert et al. ${ }^{35}$ in a phase II, randomised, double-blind, placebo-controlled study evaluated dupilumab in patients with CRSwNP refractory to INCS. Patients $(n=60)$ were randomised to 2 weekly subcutaneous dupilumab injections or placebo, and 51 patients completed the study. The group treated with

Table I. Mechanism of action, possible side effects, dose, and administration modalities of the most promising MAbs in the treatment of severe uncontrolled CRSWNP.

\begin{tabular}{|c|c|c|c|c|c|}
\hline Generic name & Brand name & Key mediator target & Mode of action & $\begin{array}{l}\text { Dose and route of } \\
\text { administration }\end{array}$ & Most common side effects \\
\hline Dupilumab & Dupixent & $\begin{array}{l}\text { IL-4 and IL-13R: } \\
\text { involved in Th2 differentiation; } \\
\text { class switching of B cells } \\
\text { to plasma cells and IgE } \\
\text { production; barrier disruption and } \\
\text { microbiome imbalance; tissue } \\
\text { remodelling and polyp formation; } \\
\text { eosinophils trafficking to tissues }\end{array}$ & $\begin{array}{l}\text { Anti-IL-4 MAb; targets the } \\
\text { IL-4 receptor } \alpha \text { subunit } \\
\text { to inhibit IL-4 and IL-13 } \\
\text { cytokines central to Th2 } \\
\text { mediated inflammation }\end{array}$ & $\begin{array}{l}\text { Subcutaneous injection, } \\
300 \text { mg every } 2 \text { week } \\
\text { Device auto-injector. } \\
\text { Allowed home } \\
\text { administration }\end{array}$ & $\begin{array}{l}\text { Injection site reaction, } \\
\text { conjunctivitis, } \\
\text { eosinophilia transitory } \\
\text { (<2\% of cases) }\end{array}$ \\
\hline Omalizumab & Xolair & $\begin{array}{c}\text { IgE: } \\
\text { involved in T2 inflammatory } \\
\text { cascade. Activating type } 2 \\
\text { inflammatory cells such as mast } \\
\text { cells, basophils, and eosinophils }\end{array}$ & $\begin{array}{l}\text { Anti-IgE MAb; it binds Fc } \\
\text { region of IgE, reducing } \\
\text { circulating IgE; down- } \\
\text { regulating FceRl and } \\
\text { FceRIl in inflammatory } \\
\text { cells. It is able to inhibit } \\
\text { type } 2 \text { inflammation } \\
\text { through several } \\
\text { mechanisms of action }\end{array}$ & $\begin{array}{l}\text { Subcutaneous injection } \\
\text { every 2-4 weeks } \\
\text { Dosing and frequency } \\
\text { level is determined by } \\
\text { serum total lgE level and } \\
\text { body weight }\end{array}$ & $\begin{array}{l}\text { Headache, dizziness, } \\
\text { arthralgia, abdominal pain } \\
\text { upper and injection site } \\
\text { reactions }\end{array}$ \\
\hline Mepolizumab & Nucala & $\begin{array}{l}\mathrm{LL}-5 \text { : } \\
\text { key mediator in chemotaxis, } \\
\text { differentiation, activation, and } \\
\text { survival of eosinophil }\end{array}$ & $\begin{array}{l}\text { Anti-IL-5 MAb; blocks } \\
\text { the binding of IL-5 to } \\
\text { the alpha chain of the } \\
\text { IL-5 receptor complex } \\
\text { expressed on the surface } \\
\text { of eosinophil cells, inhibits } \\
\text { IL-5 signaling and reduces } \\
\text { eosinophil activation, } \\
\text { proliferation, recruitment, } \\
\text { maturation, and survival }\end{array}$ & $\begin{array}{l}100 \text { mg monthly } \\
\text { subcutaneous injections } \\
\text { regardless of weight }\end{array}$ & $\begin{array}{l}\text { Nasopharyngitis } \\
\text { headache, } \\
\text { injection site reaction }\end{array}$ \\
\hline Benralizumab & Fasenra & $\begin{array}{l}\text { Eosinophils IL-5R } \alpha \text { : } \\
\text { key effector cells in Type } 2 \\
\text { inflammation }\end{array}$ & 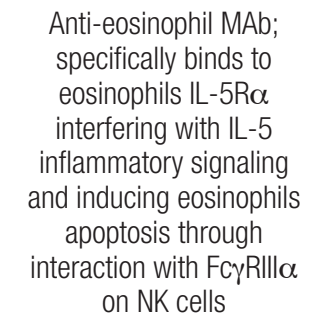 & $\begin{array}{l}\text { Subcutaneous injection } \\
30 \text { mg once every } \\
4 \text { weeks for the } \\
\text { first } 3 \text { doses, then } \\
\text { subsequently once } \\
\text { every } 8 \text { weeks }\end{array}$ & $\begin{array}{c}\text { Asthma, pharyngitis, URTI, } \\
\text { headache, Injection site } \\
\text { reaction }\end{array}$ \\
\hline
\end{tabular}


Table II. Literature evidence and approval of MAbs in the treatment of severe uncontrolled CRSwNP.

\begin{tabular}{|c|c|c|c|c|c|}
\hline Generic name & $\begin{array}{l}\text { Brand } \\
\text { name }\end{array}$ & Phase II trials & $\begin{array}{l}\text { Phase III trials } \\
\text { inclusion criteria }\end{array}$ & $\begin{array}{l}\text { Demonstrated } \\
\text { therapeutic effects }\end{array}$ & $\begin{array}{l}\text { Development status } \\
\text { and approval }\end{array}$ \\
\hline Dupilumab & Dupixent & $\begin{array}{c}\text { Bachert, et al. JAMA 2016;315:469- } \\
\text { 479. https://doi.org/10.1001/ja- } \\
\text { ma.2015.19330 } 35\end{array}$ & $\begin{array}{l}\text { Bachert C, SINUS-24 and } \\
\text { SINUS-52. Lancet } 2019{ }^{41} \\
\text { Prior SCS in past } 2 \text { years OR } \\
\text { prior NP surgery } \\
\text { NPS } \geq 5 \\
\text { Nasal congestion/blockage/ } \\
\text { obstruction or symptom } \\
\text { severity }=2 / 3\end{array}$ & $\begin{array}{l}\text { Rapid and sustained Reduction } \\
\text { in nasal polyp and CT } \\
\text { scores. } \\
\text { Improvement in olfaction, } \\
\text { in nasal congestion } \\
\text { scores, symptoms, and QOL } \\
\text { (SNOT-22), pulmonary function } \\
\text { (FEV1), and asthma control } \\
\text { test score (ACQ6). } \\
\text { Reduction of the need of SCS } \\
\text { and of surgery. }\end{array}$ & $\begin{array}{c}\text { Phase } 3 \text { trials pub- } \\
\text { lished, FDA approval on } \\
\text { June } 26^{\text {th }} 2019 \text {, EMA } \\
\text { approval on October } \\
26^{\text {th }}, 2019 \text { and AIFA } \\
\text { approval } 9^{\text {th }} \text { December } \\
2020\end{array}$ \\
\hline Omalizumab & Xolair & $\begin{array}{c}\text { Gevaert. J Allergy Clin Immu- } \\
\text { nol 2013;131:110-6. https://doi. } \\
\text { org/10.1016/j.jaci.2012.07.047 }\end{array}$ & $\begin{array}{c}\text { Gevaert P POLYP } 1 \text { and } \\
\text { POLYP } 250 \\
\text { No requirement for prior SCS } \\
\text { OR NP surgery } \\
\text { NPS } \geq 5 \\
\text { SNOT } 22 \geq 20 \\
\text { NCS } \geq 2 \text { at screening }\end{array}$ & $\begin{array}{l}\text { Rapid and sustained improve- } \\
\text { ments in mean NPS and daily } \\
\text { NCS at Week } 24 . \\
\text { Improvements in SNOT-22 and } \\
\text { patient-reported health-related } \\
\text { QoL (HRQoL), sense of smell } \\
\text { score, total nasal symptom } \\
\text { score (TNSS). } \\
\text { Reduction in need } \\
\text { for surgery. }\end{array}$ & $\begin{array}{c}\text { Phase } 3 \text { trials conduct- } \\
\text { ed published, } \\
\text { FDA approval in De- } \\
\text { cember } 2020 \\
\text { EMA approval in July } \\
2020\end{array}$ \\
\hline Mepolizumab & Nucala & $\begin{array}{c}\text { Gevaert, et al. J Allergy Clin Immunol } \\
\text { 2011;128:989-995. } \\
\text { https://doi.org/10.1016/j.ja- } \\
\text { ci.2011.07.056 }{ }^{37} \\
\text { Bachert, et al. J Allergy Clin Immunol } \\
\text { 2017;140:1024-1103. } \\
\text { https://doi.org/10.1016/j.ja- } \\
\text { ci.2017.05.044 }{ }^{38}\end{array}$ & $\begin{array}{c}\text { SYNAPSE study (GSK Study } \\
\text { ID: 205687; NCT03085797) } \\
\text { Concluded in } 2020^{51} \\
\text { Prior NP surgery in past } 10 \\
\text { years } \\
\text { NPS } \geq 5 \\
\text { VAS symptom score }>7\end{array}$ & $\begin{array}{l}\text { Improvement in nasal polyp } \\
\text { score and VAS score. } \\
\text { Improvement in SNOT-22, } \\
\text { overall VAS score } \\
\text { and VAS symptom score } \\
\text { for loss of smell. } \\
\text { Reduction in required sinus } \\
\text { surgery. } \\
\text { Reduction of proportion of } \\
\text { subjects } \\
\text { requiring systemic steroids } \\
\text { for nasal polyps. } \\
\text { Reduction of blood eosinophils } \\
\text { without complete depletion. }\end{array}$ & $\begin{array}{l}\text { Phase } 3 \text { concluded in } \\
2020 \\
\text { FDA accepted GSK fil- } \\
\text { ing in } 2020 \text { - approval } \\
\text { ongoing } \\
\text { EMA accepted GSK fil- } \\
\text { ing in } 2020 \\
\text { Approval ongoing }\end{array}$ \\
\hline Benralizumab & Fasenra & $\begin{array}{c}\text { Chitguppi. Am J Rhinol } \\
\text { Allergy 2020. https://doi. } \\
\text { org/10.1177/1945892420978351 } \\
\text { Lombardo. } \\
\text { Int J Immunopathol Pharmacol } 2020 . \\
\text { https://doi. } \\
\text { org/10.1177/2058738420950851 }{ }^{40} \\
\text { Tversky, et al. Clin Exp Allergy } 2021 . \\
\text { https://doi.org/10.1111/cea.13852 }\end{array}$ & $\begin{array}{c}\text { OSTRO (NCT03401229) }{ }^{62} \\
\text { Prior SCS use or NP surgery } \\
\text { NPS } \geq 5 \\
\text { NCS }=2 / 3 \\
\text { SNOT } 22 \geq 30 \\
\text { ORCHID (NCT04157335) }{ }^{63} \\
\text { (trial ongoing). } \\
\text { NPS } \geq 5 \\
\text { NCS } \geq 2 \% \\
\text { SNOT- } 22 \geq 20 \\
\text { Comorbid asthma } \\
\text { Eosinophils } \geq 150 \text { cells or } \\
>2 \%\end{array}$ & $\begin{array}{l}\text { Improvement in NPS, nasal } \\
\text { blockage score, Lund-Mackey } \\
\text { CT score, SNOT-22, NRS, AER, } \\
\text { pulmonary function (FEV1), } \\
\text { OCS daily use in real-life } \\
\text { SEA patients with comorbid } \\
\text { CRSwNP. } \\
\text { Improvement in NPS, NBS, } \\
\text { SNOT-22, Lund-Mackey CT } \\
\text { score, UPSIT score in patient } \\
\text { with severe CRSwNP. }\end{array}$ & $\begin{array}{l}\text { Phase } 3 \text { trials on-going } \\
\text { FDA to be determined } \\
\text { EMA to be determined } \\
\text { AIFA to be determined }\end{array}$ \\
\hline
\end{tabular}

SCS: systemic corticosteroids; OCS: oral corticosteroids; NPS: nasal polyps score; NCS: nasal congestion score; SNOT: sino nasal outcomes test; VAS visual analogical scale; FDA: Food and Drug Administration; EMA: European Medicines Agency; AlFA: Italian Agency of Drugs.

UPSIT: University of Pennsylvania smell identification test; CRSwNP chronic rhinosinusitis with nasal polyps; SEA: severe eosinophilic asthma; QoL: quality of life; TNSS: total nasal symtpoms score; NRS: numerical rating scale; AER: asthma exacerbation rate. 
dupilumab had a significant reduction in polyp size (primary endpoint), which was clinically observable from the 4th week of treatment. Later, the SINUS-24 and SINUS-52 phase 3 studies ${ }^{41}$ demonstrated the efficacy and safety of subcutaneous dupilumab $300 \mathrm{mg}$ administered every 2 weeks versus placebo in severe CRSwNP not controlled with standard of care (INC, previous SCS and/or surgery). Patients obtained significant improvements in all primary and secondary endpoints at week 24 and 52. A significant improvement was observed in treated patients compared to placebo in terms of nasal congestion/obstruction severity, nasal polyps score (NPS), sinus opacification and loss of smell. For the two primary endpoints, NPS and NCS, significant improvement was observed as early as week 4 of treatment. For UPSIT score, significant improvement was observed at week 2 of observation, with continued improvement evident up to the end of treatment in both studies for all endpoints. For loss of smell, $62 \%$ of patients treated with dupilumab changed their smell status from anosmic to non-anosmic. Lastly, dupilumab treatment resulted in a significant reduction of SCS use and the need for revision surgery compared to placebo.

Supporting dupilumab's mechanism of action, analyses of biomarkers in patients treated with dupilumab in SINUS-52 showed a consistent decrease in concentrations of serum total IgE, periostin, TARC and plasma eotaxin-3 at weeks 24 and 52 and in concentrations of ECP, total IgE, eotaxin-3, and IL-5 in nasal secretions at week 24. Furthermore, in SINUS-24, the suspension of dupilumab $v s$ placebo at week 24 led to loss of efficacy on all endpoints observed up to week 48 .

Finally, literature data supports the benefits of adding dupilumab to daily standard of care in patients with CRSwNP as a novel approach in treating the entire spectrum of clinical manifestations of the disease, as well as the frequently associated type 2 lower airway comorbidities ${ }^{42-44}$. Dupilumab was the first biologic approved by the Food and Drug Administration (FDA) on June $26^{\text {th }}, 2019$ to treat in adults with CRSwNP not adequately controlled. The European Medicines Agency (EMA) released a favourable opinion on dupilumab on October 26th, 2019 as add-on therapy with INCS for the treatment of adults with severe CRSwNP for whom therapy with systemic cosrticosteroids and/or surgery do not provide adequate disease control. In Italy, dupilumab was approved by the Italian Agency of Drugs (AIFA) on December $9^{\text {th }}, 2020$ for adult patients with severe CRSwNP (assessed by an NPS score $\geq 5$ or a SNOT-22 score $\geq 50$ ) for whom therapy with SCS and/or surgery do not provide adequate disease control, in addition to background therapy with INCS.

\section{Omalizumab (anti-IgE antibody)}

Omalizumab is the longest-lived monoclonal antibody approved since 2003 for the treatment of moderate to severe persistent allergic asthma in more than 90 countries ${ }^{45}$. It was designed to treat IgE-mediated disease by reducing the concentration of free $\operatorname{IgE}$ in blood and tissue ${ }^{47-49}$. Given multiple potential mechanisms by which omalizumab may limit Type 2 inflammation it was investigated not only in asthma but also in CRSwNP. Phase III trials (POLYP 1 and POLYP 2) ${ }^{50}$ were conducted in parallel to evaluate the efficacy and safety of omalizumab in adults with severe uncontrolled CRSwNP refractory to treatment with INCS. The trials compared the effects of omalizumab (75-600 mg s.c. every 2 or 4 weeks, adjusted according to pre-treatment serum $\operatorname{IgE}$ and body weight) to placebo in patients with severe CRSwNP not controlled with standard of care background therapy by INCS. Both POLYP-1 $(\mathrm{n}=138)$ and POLYP-2 $(\mathrm{n}=127)$ met their co-primary endpoints: omalizumab-treated patients achieved statistically significant improvements in mean NPS and daily NCS at Week 24 versus placebo. Moreover, the improvements were observed as early as week 4 in both studies, demonstrating a rapid effect and maintained in time. Key secondary endpoints were also met including SNOT-22, total nasal symptom score (TNSS), sense of smell (assessed by UPSIT), posterior and anterior rhinorrhea scores for post-nasal drip and runny nose. Improvements above placebo were observed for most secondary endpoints as early as Week 4 (Week 8 for UPSIT) and were maintained over the 24-week treatment period. In addition, reduced need for surgery by Week 24 (NPS of $\leq 4$ and MCID improvement in SNOT-22) was observed in $19 \%$ of omalizumab-treated patients versus $3 \%$ of placebo-treated patients in POLYP-1 and $17 \%$ versus $3 \%$ in POLYP- $2^{50}$.

An open-label extension study ${ }^{50}$ for participants in POLYP-1 and POLYP-2 studies was conducted to evaluate the safety, efficacy and durability of response of omalizumab in adult patients with CRSwNP and inadequate responders to INCS. Patients who completed either POLYP-1 or POLYP-2 were eligible for this study $(\mathrm{n}=249)$. All patients received treatment with omalizumab for 28 weeks, followed by a 24 -week period off treatment to assess the recurrence of nasal polyposis. The extension study results show that omalizumab treated patients improved in term of NPS and SNOT-22 scores. On the other hand, when ceasing the treatment NPS, NCS and SNOT-22 progressively worsened, although they never returned to pre-treatment levels. Therefore, long-term benefits of the therapy have been demonstrated. Omalizumab was generally well tolerated with overall rates of adverse events (AE) comparable to those observed in previous Phase III trials ${ }^{48}$. No new or unexpected AEs were observed. 
On November $30^{\text {th }}, 2019$, the FDA approved omalizumab for the treatment of CRSwNP. Furthermore, the EMA gave a favourable opinion of omalizumab on July $7^{\text {th }}, 2020$ in Europe.

\section{Biologics Targeting IL-5 pathways (Mepolizumab, Benralizumab)}

\section{Mepolizumab}

The clinical development programme of mepolizumab in CRWwNP was composed of two phase 2 placebo-controlled studies that evaluated intravenous mepolizumab $750 \mathrm{mg}$ in patients with severe nasal polyps ${ }^{37,38}$, and by the phase 3 SYNAPSE study which investigated the efficacy and safety of subcutaneous mepolizumab $100 \mathrm{mg}$ administered via pre-filled syringe in adult CRWwNP ${ }^{51}$.

Bachert et al. ${ }^{38}$ in the phase II study evaluated intravenous mepolizumab $750 \mathrm{mg}$ every 4 weeks in 105 patients with severe bilateral CRSwNP requiring surgery according to predefined criteria (NPS $>3$ or more in 1 nostril and a VAS $>7$ ). The authors demonstrated that mepolizumab led to a significant reduction in the need for surgery and a significant improvement of symptoms $v s$ placebo. Gevaert et al. ${ }^{37}$ evaluated intravenous mepolizumab $750 \mathrm{mg}$ every 4 weeks in 30 adults with severe uncontrolled CRSwNP. Mean total nasal polyp score was significantly improved in $60 \%$ of mepolizumab-treated patients compared to $10 \%$ of the placebo group.

Howarth et al. ${ }^{51}$ described results of a post hoc analysis of the MUSCA study ${ }^{52}$ and a meta-analysis of MUSCA and MENSA ${ }^{53}$; their combined objective was to determine the change in HRQOL in mepolizumab-treated patients with severe eosinophilic asthma (SEA) with or without NP. For the MUSCA post hoc analysis, 422 patients completed the SNOT-22 questionnaire at baseline and were included. Overall, $19 \%$ of patients $(n=80)$ had NP; in these patients mepolizumab and placebo significantly reduced the mean SNOT-22 from baseline to week 24. For the meta-analysis of MENSA/MUSCA, 166 of 936 patients (18\%) had NP at screening. Patients with SEA and concomitant NP had a phenotype that showed greater benefit with mepolizumab compared with patients with SEA in the absence of NP.

The phase 3 SYNAPSE study ${ }^{54}$ was a 52-week, randomised, double-blind, placebo-controlled, parallel group study of subcutaneous mepolizumab $100 \mathrm{mg}$ in 407 adult patients with highly symptomatic CRSwNP uncontrolled by previous surgery and treated with INCS. Eligible patients had at least 1 prior surgery in the past 10 years, recurrent nasal polyps despite treatment with standard of care and in need of nasal polyp surgery (overall VAS $>7$ and an NPS of at least 5 with a minimum score of 2 in each side). The re- sults were presented firstly at the congress of the European Respiratory Society, September 7-9, $2020{ }^{55}$. Mepolizumab $100 \mathrm{mg}$ administered subcutaneously demonstrated significant improvement in terms of size of nasal polyps and nasal obstruction at week 52 compared with placebo.

Based on these data, in October 2020, EMA accepted regulatory submissions seeking approval for the use mepolizumab in CRWwNP. Mepolizumab is currently not indicated for the treatment of CRSwNP.

\section{Benralizumab}

Benralizumab is a humanised monoclonal antibody that binds to the alpha subunit of the IL-5 receptor (IL-5R or CD125) which is expressed on different cells like eosinophils, basophils and type-2 innate lymphoid cells (ILC2). The mechanism of action of benralizumab, different from other monoclonal antibodies binding IL-5, is not limited to interference with IL-5 inflammatory pathways. Indeed, benralizumab is able to induce an antibody-dependent cellular cytotoxicity (ADCC) by binding to the Fc $\gamma$ RIII $\alpha$ receptor expressed on natural killer (NK) cells. This second mechanism of action produces a direct, rapid and nearly complete eosinophil depletion both in peripheral blood and bronchial tissue ${ }^{56}$. The Phase III studies, SIROCCO and CALIMA ${ }^{57,58}$, demonstrated the efficacy and safety of benralizumab in significantly reducing annualised exacerbations rates, improving lung function and disease control $v s$ placebo as add-on therapy to high-dosage ICS/LABA in patients with SEA and blood eosinophil counts $\geq 300$ cells/ microliter.

A growing body of evidence suggests that benralizumab may exert a rapid and effective therapeutic action in patients with SEA and concomitant relapsing nasal polyposis ${ }^{39}$. Canonica et al. ${ }^{59}$ presented the results of a sub-study of ANDHI phase III-b trial at EAACI congress in 2020, involving 153 patients with SEA and CRSwNP as comorbidity, demonstrating the efficacy of benralizumab in improving SNOT-22 scores. Clinically relevant improvements in CRSwNP symptoms were observed following the first dose and maintained over time.

Real world studies and case reports have confirmed the efficacy and safety of benralizumab in this population in clinical practice. Lombardo et al. ${ }^{40}$ assessed a cohort of 10 SEA patients with CRSwNP treated with benralizumab, demonstrating significant reduction of endoscopic Nasal Polyp Score (NPS), Lund-Mackay Score and SNOT-22 after 24 weeks. Bagnasco et al. ${ }^{60}$ in a real-world evaluation in 34 patients with SEA and CRSwNP, confirmed the effectiveness of benralizumab on SNOT-22 reduction, with $8 / 26$ patients (31\%) recovering from anosmia after 6 months of treatment. 
In a phase II randomised, double-blind, placebo-controlled 20-week trial ${ }^{61}$, benralizumab led to significant improvement in endoscopic NPS, CT score, SNOT-22 and UPSIT score $v s$ baseline in severe CRSwNP patients refractory to standard therapies with at least one previous polypectomy. These results suggested that benralizumab, which targets eosinophils directly, may have a role in the treatment of patients with severe uncontrolled CRSwNP.

Currently, a Phase III development programme which includes the completed OSTRO study ${ }^{62}$ and the ongoing ORCHID trial ${ }^{63}$ is assessing the efficacy and safety of benralizumab in patients with severe CRSwNP with or without asthma. On September 2020, a press release revealed that the OSTRO study Benralizumab met both its co-primary endpoints of reduced nasal polyp size and nasal congestion score (NCS) vs placebo as add-on therapy to standard of care in patients with severe bilateral nasal polyposis. Benralizumab for use in CRSwNP is expected to be approved in the next few years.

Basing on the data of phase 3 studies, biologics approved and oncoming in the next future should be considered as add-on therapy to local corticosteroids when control of the disease is not achieved

even after oral corticosteroids and/or surgery.

All the members of the committee agree that biologics are recommended when Type 2 inflammation is highly likely to be the dominant endotype of severe uncontrolled CRSwNP.

ENT physicians involved in the prescriptions of biologics should have a clear understanding not only about sinonasal inflammatory patterns driving diffuse CRSwNP, but also about the mechanism of action, possible side effects, dose and administration modalities of biologics.

\section{Recommendations for biologics in uncontrolled severe CRSwNP}

Several trials have investigated the efficacy of biologics in the treatment of CRSwNP with encouraging results. The approval of some biologics by the FDA in the treatment of severe uncontrolled CRSwNP even without asthma has stimulated discussion in the medical community, expecting a quick entry in the market not only for dupilumab, but also for other monoclonal antibodies. For this reason, recent guidelines ${ }^{1,64}$ gave full consideration about selection criteria of the ideal candidate for biologics and their place in current care pathways. In 2019, the EUFOREA team ${ }^{64}$ suggested for the first time five criteria as crucial to select CRSwNP patients who are eligible for biologics. In February 2020, EPOS guidelines ${ }^{1}$ further defined these criteria introducing specific cut-offs: evidence of type 2 disease (tissue eosinophils $\geq 10 / \mathrm{hpf}$ or blood eosinophils $\geq 250$ /microliter or total $\operatorname{IgE} \geq 100$ ), need for at least two courses of SCS per year or long term ( $>3$ months) low dose steroids or contraindication to systemic steroids, significantly impaired quality of life (SNOT-22 $\geq 40$ ), anosmic on smell test and/or comorbid asthma needing regular inhaled corticorsteroid. EPOS $2020{ }^{1}$ concluded that biologics are indicated in patients with bilateral nasal polyps, who had sinus surgery or were not fit for surgery and who had three of the listed criteria. The authors were involved in an extensive discussion of whether there was a role for biologics in patients without previous sinus surgery accepting that it was possible in exceptional circumstances. Criteria established by current guidelines ${ }^{1,19}$ refers use of biologics in patients with severe and uncontrolled $C R S w N P$ bringing to light the increasing necessity of identifying subgroups of patients who are eligible for biologics and of a clear definition of severe uncontrolled CRSwNP.

The concept of disease control has been a major critical point to optimise CRS management and was introduced for the first time at EPOS $2012{ }^{5}$ combining the following parameters: control of the four major sino-nasal symptoms (nasal blockage, rhinorrhoea/postnasal drip, facial pain/pressure, smell), sleep disturbance and/or fatigue, endoscopic aspect of nasal mucosa and medical intake. EPOS $2020{ }^{1}$ criteria specified that the 4 major symptoms should be specifically related to CRS and not to other reasons ${ }^{65}$. EPOS $2020{ }^{1}$ assumed as "difficult-to- treat" those in whom an acceptable level of control was not achieved despite appropriate surgery, INCS, and up to 2 brief courses of antibiotics or SCS in the last year, or long term $(>3$ months) low dose steroids. The EPOS 2020 panel defined "short" courses of SCS as at least 7-21 days.

In the latest EUFOREA $2020^{19}$, "uncontrolled CRSwNP" was defined as "persistent or recurring despite long-term INCS and having received at least one course of SCS in the preceding 2 years (or having a medical contraindication or intolerance to SCS) and/or previous sinonasal surgery (unless having a medical contraindication or being unwilling to undergo surgery)". The EUFOREA group ${ }^{19}$ suggested that a short course of oral corticosteroids should be of a minimum of 5 days at a dose of $0.5-1 \mathrm{mg} / \mathrm{kg} / \mathrm{day}$ or more. In this last definition, the need for corticosteroids was lowered based on evaluation of baseline criteria of subjects included in the Phase 3 studies. The EUFOREA group further confirmed that long term low does SCS are not recommended for CRSwNP. This panel believes that a specific discussion should be opened by the medical community on the right dose of SCS to consider as maximal per year. Given the considerable variability of ENT physicians in prescribing SCS in terms of daily dose and length 
of short courses, we believe that it may be more appropriate to refer to the yearly cumulative dose in the last year as for asthma patients. Bourdin et al. ${ }^{66}$ in fact suggested that "a yearly cumulative OCS dose above 1 gram should be considered unacceptable in severe asthma and should make the case for referral".

The concept of severity of disease over the years has been mainly based on the impact of disease on quality of life and its local extension. Because CRSwNP has a wide variability of presentation and the severity may vary significantly between individuals, several authors investigated how to measure it and its definition is becoming increasingly important. Validated QOL markers have been utilised to identify eligible CRSwNP patients for Phase 3 studies with biologics, with VAS and SNOT-22 being the most commonly used; for this reason, they are currently adopted to define severe CRSwNP ${ }^{67,68}$. Several nasal polyp endoscopic scoring systems have been described over the years ${ }^{69,70}$ until a total NPS was recently developed and standardised ${ }^{71}$. It has served as a co-primary outcome in clinical trials of biologics, the results are reproducible and responsive to change in severe disease and it is the most common used to evaluate the size of nasal polyps. Equally, the Lund-Mackay radiological score allows reliable assessment of the extent of disease, and like endoscopy is easily repeatable ${ }^{71}$. Evaluation of olfaction is always important to define severity of the disease. UPSIT ${ }^{72}$ is the standard clinical test used in United States, whereas the Sniffin' Sticks in Europe ${ }^{73,74}$. Both have high test-retest reliability, normative values by age and sex, and are widely used in research and clinical practice. Nasal airflow may easily be measured by peak nasal inspiratory flow (PNIF) that is an objective measure of airflow and closely correlated with nasal airway resistance. PNIF is simple to obtain, and the devices are inexpensive and can be used for repeated measurements ${ }^{75}$.

The EPOS steering group ${ }^{1}$ identified as cut offs for severe CRSwNP a VAS $>7$, SNOT-22 $>40$ and NPS $>5$. Furthermore, the EPOS guidelines suggested that also olfaction evaluation was an important parameter to take into consideration suggesting as cut-offs the specific ones for the test used and indicating a picture of anosmia. Recently, the expert EUFOREA panel ${ }^{19}$ lowered this parameter as follows: SNOT-22 $>35$, loss of smell score $(0-3)>2$ points or VAS $\geq 5$ and NPS $\geq 4$. The members of this committee believe that particular attention should be paid about cut offs of severe CRSwNP. Some concerns have been raised about this new proposed endoscopic score cut-off (NPS > 4) which seems to more properly reflect a moderate picture. Considering the fact that quality of life parameters were also lowered, we believe that future considerations should be made about this topic.
The members of the committee agree that given the importance of measuring the severity of the disease, particular attention should be paid to this aspect. The ENT should always be familiar with the most common severity indicators that should routinely be adopted in clinical practice.

Future debates should be opened about the maximal yearly SCS dose and specific cut offs for the definition of severe uncontrolled CRwNP.

\section{Multidisciplinary approach}

The recent scientific evidence clearly underlines the link between Type 2 diseases, leading to implement multidisciplinary evaluation in Type 2 inflammatory conditions. CRS healthcare often requires support from other specialists especially in severe cases. The collaboration with an allergologist, pneumologist, immunologist and rheumatologist is crucial to define endotype of the disease and coexisting Type 2 comorbidities such as atopic dermatitis, eosinophilic esophagitis or gastroenteritis, N-ERD, allergic fungal rhinosinusitis, Churg Struss Syndrome etc. ${ }^{76,77}$.

In the context of a multidisciplinary approach, the central role of the ENT in the management of CRSwNP should be underlined. The ENT has a crucial role firstly in the confirmation of the disease, in evaluating previous surgical treatment and measuring severity of the disease. Endoscopy should be considered a mainstay in the diagnosis of CRSwNP to perform an adequate phenotyping, accurate staging of the disease and adequate differential diagnosis. It should be noted that the possible coexistence of inverted papilloma and diffuse CRS with nasal polyps should be always excluded even if rare ${ }^{68-71}$.

\section{CT scan without endoscopy is not sufficient to confirm the diagnosis of CRSwNP.}

\section{Particular attention should be paid in the definition of the} severity of comorbidities.

Biologics for CRSwNP and concomitant severe asthma should be mainly managed by asthma specialists, while on the other hand for patients with severe uncontrolled CRSwNP without asthma/mild moderate asthma the role of the ENT specialist should be central. Close collaboration is always recommended to manage comorbid patients.

\section{Surgery and biologics}

The commission believes that the role of surgery should not be underestimated, but rather that its role should be reconsidered in the light of new therapeutic opportunities. ESS usually leads to a very quick relief of symptoms and in particular of nasal obstruction, and it further improves control of the disease obtained by long term local corticosteroids. 
Sinuses are, in fact, better accessible to local treatments after surgery increasing disease control by long term use of INCS (in 60\%-70\% of cases, disease does not recur within 5 years) ${ }^{35,78}$. For this reason, it is very important to distinguish between first-time and revision surgery. Another crucial factor that may influence the decision-making algorithm is the coexistence of other Type 2 comorbidities and in particular asthma (the one most associated with CRSwNP). The severity of comorbidities should be established because different scenarios may be faced that need to be assessed separately ${ }^{16,17}$.

Patients with severe uncontrolled CRSwNP mainly managed by medical treatment and never treated by surgery with or without mild moderate asthma

If a patient has never undergone surgery, ESS should be taken into consideration because it improves control of the disease by INCS spreading their distribution to all sinonasal mucosa. Based on this assumption one could infer that if patients never received surgery probably control by INCS may not be fully achieved ${ }^{78,79}$.

The members of the commission believe that in a patient with uncontrolled severe CRSwNP treated mainly with long term INCS and brief cycles of SCS and who never received surgery, ESS should be taken into consideration as first line treatment, although the following circumstances should be considered as limitations: contraindications to surgery because of patient's general condition (severe cardiopathy, severe haemorrhagic risk, high risks for general anaesthesia etc.); patients refusing treatment by surgery; relevant side effects using INCS and SCS; patient preferences after adequate counseling on all therapeutic options.

Finally, one last matter should be covered in the near future. Taking into consideration that some authors $34,80,81$ have demonstrated that disease control by ESS plus longterm local corticosteroids is very difficult to achieve in the presence of negative predictors of surgical outcomes (asthma, allergy, blood eosinophilia, ASA triad, high load local inflammation, specific preoperative inflammatory patterns) ${ }^{34}$, some speculate that in this subgroup of patients biologics should be taken into consideration even as first line treatment. Nevertheless, at the moment, there is insufficient literature evidence to support this statement and specific trials should be properly designed to verify this hypothesis.

Patients with severe CRSwNP uncontrolled after medical and surgical treatments with or without mild moderate asthma

This may be a different scenario if CRSwNP patients already underwent at least one previous surgery. In this situation, the ENT specialist has a central role in clarifying if surgery was appropriate or not by a careful evaluation of CT and endoscopic findings. It is very important to consider the surgical technique used in the previous treatments. Unfortunately, literature data about rate of success surgical management of CRSwNP varies significantly mainly because authors have not differentiated patients based on their phenotypes and because they adopted different criteria to define recurrence and disease control ${ }^{82}$. In addition, revision ESS rates have changed over the last decade tailoring the extent of surgery and optimising adjuvant post-operative therapy ${ }^{83}$. Recurrence after a simple polypectomy should be understood in a different way compared to a patient who underwent a more extended approach. It should be careful evaluated if surgery was commensurate to the severity of the phenotype.

In case of uncontrolled disease after previous appropriate surgery and good adherence to INCS the shift to a biologic should be advised. On the other hand, especially in cases in which a simple polypectomy was performed and the ethmoidal labyrinth was not adequately opened, the possibility of revision surgery should be discussed with the patient. The commission agreed that in this situation the ENT specialist should have a clear idea of which additional surgical goals may be achieved to improve access to sinus cavities including, for example, a partial middle turbinectomy if not performed previously.

Another important factor to take into consideration is the timing of recurrence and control of symptoms that patients experienced over the years after surgery. Recently, some authors ${ }^{84}$ have demonstrated that patients presenting with a symptomatic recurrence within 3 years of surgery have a high risk of treatment failure, defined as the need for further surgery. Surgeons should distinguish between revision surgery that is required within a short period from the first procedure and a revision that is required after several years with good control of the disease. In these cases, we believe that the patient should be involved into the decision to repeat surgery or to shift towards treatment with biologics. If patients experience a long period of symptoms controlled by surgery and INCS, a revision surgery can be discussed with the patient. In this context, the presence of clinical predictors of poor surgical outcomes may help the patient and the surgeon towards the choice of biologics. Other factors may influence the choice such age of the patient and his/her preferences.

In case of patients who underwent multiple surgeries with a severe impact on quality of life and who experienced a short interval of symptoms control between interventions, 
the use of biologic is recommended whatever the endoscopic nasal polyps score at the moment of the evaluation. Similarly, in patients already treated by surgery and who reported major complications after ESS, the shift to biologics is recommended.

This committee believes that adequate counselling is always recommended in order to discuss all the alternative treatments and possibilities with the patient based on control and severity of disease. Based on the new personalised medicine requirement, patients should participate in the decision to start with a specific treatment.

We believe that surgery still plays an important role not only in order to optimise control of the disease, but also for the dynamics between forces that range from international recommendations and payer policies to patient and physician preferences. Discussion should be opened about the possibility to use biologics as first line with surgery in case of very high polyps score to offer a better starting point to patients, even if there is insufficient evidence to support this hypothesis considering that there are no data comparing surgery in combination with biologics. In addition, the following recommendation of EUFOREA 2021 should be taken into consideration: "A fixed combination plan with surgery and biologic treatment starting in parallel or within a short time of one another is not advised, as the response of the individual patient to surgery or the biologic would be impossible to evaluate" ${ }^{19}$.

Patients with severe uncontrolled CRSwNP and comorbid uncontrolled severe asthma

A proportion of patients with severe uncontrolled CRSwNP may also have a coexisting, highly disabling Type 2 disease such as severe asthma ${ }^{85}$. In this situation, multidisciplinary discussion with an allergologist and pneumologist is essential and treatment with biologics should be mainly managed by them. In these patients, surgery may offer a better starting point to achieve quick relief of sino-nasal symptoms and asthma control as soon as possible, even if surgery should be delayed while verifying the efficacy of biologics on sino-nasal symptoms and reducing the nasal polyp score. Close cooperation is recommended during treatment to evaluate both efficacy on asthma and CRwNP. Surgery or shift to another biologic may be indicated if poor control of CRSwNP is observed after 4-6 months of treatment with biologics.

The commission agrees that if severe asthma co-exists close cooperation with a pneumologist and allergologist is highly recommended to evaluate in a multidisciplinary fashion the best way forward in term of indications and selection of biologics.

\section{Criteria to evaluate response to biologics}

EUFOREA expert panel on $2019^{64}$ first described criteria to evaluate response to biologics and specifically: reduced nasal polyps size, reduced need for SCS, improved quality of life, improved sense of smell and reduced impact of comorbidities. The same criteria were adopted by EPOS $2020{ }^{1}$. Initially authors ${ }^{86}$ agreed that the first evaluation should be set at 4 months to consider an early stopping point if treatment response is lacking, due to the high cost of these medications. More recently, the EUFOREA expert panel in $2020{ }^{19}$ prolonged the first evaluation to 6 months of treatment and specified cut-offs for each criterion. The authors specified that the treatment should be followed when a clear change for at least one of the following criteria have been met: smell score increase $>0.5$, NCS decrease $>0.5$, NPS decrease by 1 point, SNOT-22 reduction $>8.9$; VAS reduction $>2 \mathrm{~cm}$. In addition, the authors recommended to discuss improvement with the patient. If patients do not accept improvement, a salvage treatment by SCS or surgery should be considered. A proportion of patients, in fact, might need surgery that the authors ${ }^{19}$ defined as "salvage surgery under biologic protection", although there is limited data about long term benefit of this kind of approach. Otherwise, if the patients accept improvement even in case of a minimal response the treatment should be prolonged until 12 months when efficacy should be re-evaluated, and all the following definitions should be satisfied to follow treatment: NPS $<4$; $\mathrm{NCS}<2$; VAS $<5$; SNOT- $22<30$. If the criteria are not met, surgery should be performed, or a different biologic should be considered.

The EUFOREA group ${ }^{19}$ tried to standardise the evaluation of biologic efficacy and the decision to adopt based on the results and the patient's comfort and preferences. We believe that future considerations will probably be required to confirm these criteria or to confirm more or less stringent indications. Real-life experience will be crucial to support this shared decision-making model.

The commission believes that evaluation to consider response to biologics is extremely important. All the members of the committee agree that the rhinology centres involved in the prescription of the biologics should organise the right setting for proper follow-up and assessment of response to biologics.

\section{Prediction of response to biologics and biomarkers}

Biomarkers can serve as predictors of which patients will respond best to therapy and as outcome parameters during treatment in order to establish efficacy of treatment. Actually, prediction of response to biologics in an individual patient is not possible. In fact, we currently lack reliable clini- 
cal biomarkers to differentiate among CRSwNP endotypes that may differ in their response to specific biologics ${ }^{87}$. In this context, specific biomarkers should be investigated; to be clinically useful, as a predictor of the response to treatment, a biomarker must be highly predictive; it is also possible that clusters of biomarkers may be able to attain high levels of predictability, but extensive work is required to advance this field especially to be ready in the near future when more biologics will be available for severe uncontrolled CRSwNP. There is no experience on the best choice of a first biologic or a second, and there are no known limitations for blood or serum parameters for CRSwNP. Finally, no head-to-head comparisons between biologics have been performed. Future work on biomarkers may yield better tests for selecting the first drug to start with.

\section{Prediction of response to biologics basing on validated biomarkers actually is not possible.}

\section{Costs of biologics in CRSwNP}

Although multiple studies have confirmed the efficacy of biologics for treatment of CRSwNP, very limited data are currently available about cost analyses of biologics compared with the current standard of care. Brown et al. ${ }^{88}$ critically looked at the efficacy and costs of biologic therapy for CRSwNP. They found few studies addressing this topic, reporting a more robust literature in asthma compared to CRwNP. They concluded that cost-efficacy studies are ambivalent when evaluating biologics. In fact, some authors ${ }^{88}$ demonstrated that biologics tended to be cost-efficient, especially in patients who are poorly controlled with the standard of care, while several studies ${ }^{89-91}$ have underlined that costs might be better justified if pharmaceutical companies lowered prices and if clinicians focused more on subgroups such as clear responders and those requiring more frequent SCS prescriptions.

We agree on the extreme need to plan cost-efficacy studies evaluating the long-term use of biologics compared with the current standard of care for CRSwNP. Total costs of the disease account for direct and indirect costs, where direct costs refer to health care costs and indirect costs refer to lost productivity. As demonstrated in other chronic diseases, the indirect costs of CRSwNP are much greater than the direct costs because patients are usually of working age ${ }^{92}$. Recently, some authors ${ }^{93-97}$ have demonstrated significant improvement in productivity after treatment of CRS and reduction of indirect costs. Likewise, if biologics are effective, they may reduce the costs related to the burden of CRSwNP.

Finally, the cost of disease needs to consider the disease time horizon and in particular the interval time in which the patients will probably be burdened with lifelong disease. Therefore, as with any chronic condition, we cannot just focus cost estimations on short time intervals, even if longterm cost calculations and modeling are unfortunately very difficult to estimate.

The commission agrees that future studies should be planned about the cost effectiveness of new drugs.

\section{Conclusions}

In a patient with uncontrolled severe type 2 CRSwNP, if non-effective systemic medical treatment or surgery has been performed, a long-term plan using a biologic should be contemplated together with an informed patient. This plan needs to consider the endotype, comorbidities and former treatment history (long term INCS, surgeries, SCS and their efficacy, duration of effect, and adverse events). We believe that patients who are still symptomatic despite current maximal medical therapy and surgical intervention are the main focus of treatment with biologics. Based on the new developments, the physician should properly inform the patient about available alternatives involving him/her in the clinical decisions in line with the principles of precision medicine that patients will also share in decision making.

The clinical scenario may further evolve in the next months/years because other biologic will receive approval for severe CRSwNP, others are currently in the pipeline and even more targets are being identified. Future study should be oriented to characterise in which patients the single biologic may have greatest clinical efficacy. In fact, the general biomarkers of Type 2 inflammation currently adopted may help to broadly identify patients who may benefit from biologics, while ongoing research may lead to identification of new biomarkers that are useful in the selection of the right patient. For these reasons, we expect in the future that clinical algorithm and care pathways may be implemented based on improving selection criteria. Future clinical trials are needed to implement recommendations for initiation of biologics, and to compare biologics to the current standard of care and between biologic medication options.

A multidisciplinary shared airway approach can possibly identify patients who may require treatment with biologics at an earlier stage in the disease process. This may have an overall positive impact on the psychological burden of the disease on patients and healthcare service. Nevertheless, current literature data do not support use of biologics at an earlier stage in the disease process of CRS, although this scenario might change in the future. 
At present, biologics are mainly considered only as adjunct therapy in patients with severe uncontrolled CRSwNP and evidence of Type 2 disease. The exact application of biologics will continue to evolve. Combinations of biologic therapies with surgery will be probably explored. Further research into biologics $v s$ surgery as well as long-term disease control is required. It is likely that biologics will in time become an alternative for sinus surgery as currently performed. We believe that the role of biologics in conjunction with surgery, after surgery, or as an alternative to it, needs to be investigated further.

While MAbs are well tolerated with no severe adverse effects, further research is required to determine their longterm benefits, comparability to other medical treatments and potential side effects.

Physicians, patients, insurers and government payers should not ignore considerations about costs. At this time, there is minimal data examining the cost-efficacy and longterm side effects. To better understand costs, studies should be designed to evaluate if biologics may decrease costs related to severe uncontrolled CRSwNP.

\section{Acknowledgements}

We would like to thank Professor Gaetano Paludetti that encouraged and stimulated discussion of the commission about the important fields of Biologics in severe uncontrolled CRSwNP when he was President of Italian Society of Otorhinolaryngology. We finally thank Professor Paludetti for final critical revision of the manuscript.

\section{Conflict of interest statement}

The authors declare no conflict of interest.

\section{Funding}

This research did not receive any specific grant from funding agencies in the public, commercial, or not-for-profit sectors.

\section{References}

1 Fokkens WJ, Lund VJ, Hopkins C, et al. European Position Paper on Rhinosinusitis and Nasal Polyps 2020. Rhinology 2020;58:1-464. https://doi.org/10.4193/Rhin20.600

2 Divekar RD, Samant S, Rank MA, et al. Immunological profiling in chronic rhinosinusitis with nasal polyps reveals distinct VEGF and GM-CSF signatures during symptomatic exacerbations. Clin Exp Allergy 2015;45:767-778. https://doi.org/10.1111/cea.12463

3 Rank MA, Hagan JB, Samant SA, et al. A proposed model to study immunologic changes during chronic rhinosinusitis exacerbations: data from a pilot study. Am J Rhinol Allergy 2013;27:98-101. https:// doi.org/10.2500/ajra.2013.27.3850

4 Hellings PW, Akdis CA, Bachert C, et al. EUFOREA Rhinology Research Forum 2016: report of the brainstorming sessions on needs and priorities in rhinitis and rhinosinusitis. Rhinology 2017;55:202-210. https://doi.org/10.4193/Rhin17.028
5 Fokkens WJ, Lund VJ, Mullol J, et al. EPOS 2012: European position paper on rhinosinusitis and nasal polyps 2012. A summary for otorhinolaryngologists. Rhinology 2012;50:1-12. https://doi.org/10.4193/ Rhino50E2

6 Bachert C, Bhattacharyya N, Desrosiers M, et al. Burden of disease in chronic rhinosinusitis with nasal polyps. J Asthma Allergy 2021;14:127-134. https://doi.org/10.2147/JAA.S290424

7 Vlaminck S, AckeF, Prokopakis E, et al. Surgery in nasal polyp patients: outcome after a minimum observation of 10 years. Am J Rhinol Allergy 2021;35:449-457. https://doi.org/10.1177/1945892420961964

8 Vanderhaegen T, Gengler I, Dendooven A, et al. Eosinophils in the field of nasal polyposis: towards a better understanding of biologic therapies. Clin Rev Allergy Immunol 2021 Jan 26. https://doi. org/10.1007/s12016-021-08844-7. Online ahead of print.

9 Peters AT, Han JK, Hellings P, et al. Indirect treatment comparison of biologics in chronic rhinosinusitis with nasal polyps. J Allergy Clin Immunol Pract 2021;3:S2213-219800159-8. https://doi. org/10.1016/j.jaip.2021.01.031.

10 Stevens WW, Lee RJ, Schleimer RP, et al. Chronic rhinosinusitis pathogenesis. J Allergy Clin Immunol 2015;136:1442-1453. https:// doi.org/10.1016/j.jaci.2015.10.009

11 Mahdavinia M, Keshavarzian A, Tobin MC, et al. A comprehensive review of the nasal microbiome in chronic rhinosinusitis (CRS). Clin Exp Allergy 2016;46:21-41. https://doi.org/10.1111/cea.12666

12 Schleimer RP. Immunopathogenesis of chronic rhinosinusitis and nasal polyposis. Annu Rev Pathol 2017;24;12:331-357. https://doi. org/10.1146/annurev-pathol-052016-100401

13 Stevens WW, Ocampo CJ, Berdnikovs S, et al. Cytokines in chronic rhinosinusitis. role in eosinophilia and aspirin-exacerbated respiratory disease. Am J Respir Crit Care Med 2015;192:682-694. https://doi. org/10.1164/rccm.201412-2278OC

14 Lee K, Tai J, Lee SH, et al. Advances in the knowledge of the underlying airway remodeling mechanisms in chronic rhinosinusitis based on the endotypes: a review. Int J Mol Sci 2021;22:910. https://doi. org/10.3390/ijms22020910

15 Akdis CA, Bachert C, Cingi C, et al. Endotypes and phenotypes of chronic rhinosinusitis: a PRACTALL document of the European Academy of Allergy and Clinical Immunology and the American Academy of Allergy, Asthma \& Immunology. J Allergy Clin Immunol 2013;131:1479-1490. https://doi.org/10.1016/j. jaci.2013.02.036

16 Wang M, Bu X, Luan G, et al. Distinct type 2-high inflammation associated molecular signatures of chronic rhinosinusitis with nasal polyps with comorbid asthma. Clin Transl Allergy 2020;3:10-26. https:// doi.org/10.1186/s13601-020-00332-z

17 Busse WW, Kraft M, Rabe KF, et al. Understanding the key issues in the treatment of uncontrolled persistent asthma with type 2 inflammation. Eur Respir J 2021 Feb 4;2003393. https://doi. org/10.1183/13993003.03393-2020. Online ahead of print.

18 Bachert C, Gevaert P, Holtappels G, et al. Total and specific IgE in nasal polyps is related to local eosinophilic inflammation. J Allergy Clin Immunol 2001;107:607-614. https://doi.org/10.1067/ mai.2001.112374

19 Bachert C, Han JK, Wagenmann M, et al. EUFOREA expert board meeting on uncontrolled severe chronic rhinosinusitis with nasal polyps (CRSwNP) and biologics: definitions and management. J Allergy Clin Immunol 2021;147:29-36. https://doi.org/10.1016/j. jaci.2020.11.013

20 De Corso E, Baroni S, Romitelli F, et al. Nasal lavage CCL24 levels correlate with eosinophils trafficking and symptoms in chronic sino-nasal eosinophilic inflammation. Rhinology 2011;49:174-179. https://doi.org/10.4193/Rhino10.133 
${ }^{21}$ De Corso E, Settimi S, Tricarico L, et al. Predictors of disease control after endoscopic sinus surgery plus long-term local corticosteroids in CRSwNP. Am J Rhinol Allergy 2021;35:77-85. https://doi. org/10.1177/1945892420936196

22 Gelardi M, De Candia N, Quaranta N, et al. The relevance of counseling in patients with nasal polyps. Acta Otorhinolaryngol Ital 2016; 36:326-327. https://doi.org/10.14639/0392-100X-1315

23 De Corso E, Battista M, Pandolfini M, et al. Role of inflammation in non-allergic rhinitis. Rhinology 2014;52:142-149. https://doi. org/10.4193/Rhino13.102

24 Gallo S, Bandi F, Preti A, et al. Exploring the role of nasal cytology in chronic rhinosinusitis. Acta Otorhinolaryngol Ital 2020;40:368-376. https://doi.org/10.14639/0392-100X-N0711

25 De Corso E, Baroni S, Battista M, et al. Nasal fluid release of eotaxin-3 and eotaxin-2 in persistent sinonasal eosinophilic inflammation. Int Forum Allergy Rhinol 2014;4:617-624. https://doi.org/10.1002/ alr.21348

26 De Corso E, Anzivino R, Galli J, et al. Antileukotrienes improve nasoocular symptoms and biomarkers in patients with NARES and asthma. Laryngoscope 2019;129:551-557. https://doi.org/10.1002/lary.27576

27 Unsal AA, Reyes C, Biddinger P, et al. Eosinophilic mucin: a predictor for disease severity in chronic rhinosinusitis. Am J Rhinol Allergy 2021;35:187-194. https://doi.org/10.1177/1945892420943828

28 Gelardi M, Iannuzzi L, De Giosa M, et al. Non-surgical management of chronic rhinosinusitis with nasal polyps based on clinicalcytological grading: a precision medicine-based approach. Acta Otorhinolaryngol Ital 2017;37:38-45. https://doi.org/10.14639/0392$100 \mathrm{X}-1417$

29 De Corso E, Lucidi D, Cantone E, et al. Clinical evidence and biomarkers linking allergy and acute or chronic rhinosinusitis in children: a systematic review. Curr Allergy Asthma Rep 2020;20:68. https://doi.org/10.1007/s11882-020-00967-9.

30 Bandi F, Gallo S, Preti A, Mozzanica F, et al. Effects of biological therapies on chronic rhinosinusitis in severe asthmatic patients. Acta Otorhinolaryngol Ital 2020;40:435-443. https://doi. org/10.14639/0392-100X-N0716

31 De Corso E, Lucidi D, Battista M, et al. Prognostic value of nasal cytology and clinical factors in nasal polyps development in patients at risk: can the beginning predict the end? Int Forum Allergy Rhinol 2017;7:861-867. https://doi.org/10.1002/alr.21979

32 Ho J, Earls P, Harvey RJ. Systemic biomarkers of eosinophilic chronic rhinosinusitis. Curr Opin Allergy Clin Immunol 2020;20:23-29. https://doi.org/10.1097/ACI.0000000000000602

33 Posteraro B, Scarano E, La Sorda M, et al. Eosinophilic fungal rhinosinusitis due to the unusual pathogen Curvularia inaequalis. Mycoses 2010;53:84-88. http://doi.org/10.1111/j.1439-0507.2008.01671.x

34 De Corso E, Baroni S, Lucidi D, et al. Nasal lavage levels of granulocyte-macrophage colony-stimulating factor and chronic nasal hypereosinophilia. Int Forum Allergy Rhinol 2015;5:557-562. https://doi. org/10.1002/alr.21519

35 Bachert C, Mannent L, Naclerio RM, et al. Effect of subcutaneous dupilumab on nasal polyp burden in patients with chronic sinusitis and nasal polyposis: a randomized clinical trial. JAMA 2016;315:469479. https://doi.org/10.1001/jama.2015.19330

36 Gevaert P, Calus L, Van Zele T, et al. Omalizumab is effective in allergic and nonallergic patients with nasal polyps and asthma. J Allergy Clin Immunol 2013;131:110-6.e1. https://doi.org/10.1016/j. jaci.2012.07.047

37 Gevaert P, Van Bruaene N, Cattaert T, et al. Mepolizumab, a humanized anti-IL-5 mAb, as a treatment option for severe nasal polyposis. J Allergy Clin Immunol 2011;128:989-995.e1-8. https://doi. org/10.1016/j.jaci.2011.07.056
38 Bachert C, Sousa AR, Lund VJ, et al. Reduced need for surgery in severe nasal polyposis with mepolizumab: randomized trial. J Allergy Clin Immunol 2017;140:1024-1031.e14. https://doi.org/10.1016/j. jaci.2017.05.044

39 Chitguppi C, Patel P, Gandler A, et al. Effect of benralizumab in patients with severe eosinophilic asthma and chronic rhinosinusitis with nasal polyps: acase series. Am JRhinolAllergy 2020;10:1945892420978351. https://doi.org/10.1177/1945892420978351

40 Lombardo N, Pelaia C, Ciriolo $M$, et al. Real-life effects of benralizumab on allergic chronic rhinosinusitis and nasal polyposis associated with severe asthma. Int $\mathrm{J}$ Immunopathol Pharmacol 2020;34:2058738420950851. https://doi. org/10.1177/2058738420950851

${ }^{41}$ Bachert C, Han JK, Desrosiers M, et al. Efficacy and safety of dupilumab in patients with severe chronic rhinosinusitis with nasal polyps (LIBERTY NP SINUS-24 and LIBERTY NP SINUS-52): results from two multicentre, randomised, double-blind, placebocontrolled, parallel-group phase 3 trials. Lancet 2019;394:1638-1650. https://doi.org/10.1016/S0140-6736(19)31881-1

42 Laidlaw TM, Bachert C, Amin N, et al. Dupilumab improves upper and lower airway disease control in chronic rhinosinusitis with nasal polyps and asthma. Ann Allergy Asthma Immunol 2021;16:S1081120600020-X. https://doi.org/10.1016/j.anai.2021.01.012

43 Bachert C, Zinreich SJ, Hellings PW, et al. Dupilumab reduces opacification across all sinuses and related symptoms in patients with CRSwNP. Rhinology 2020;58:10-17. https://doi.org/10.4193/ Rhin 18.282

44 Kim J, Naclerio R. Therapeutic potential of dupilumab in the treatment of chronic rhinosinusitis with nasal polyps: evidence to date. Ther Clin Risk Manag 2020;16:31-37. https://doi.org/10.2147/ TCRM.S210648

45 Schulman ES. Development of a monoclonal anti-immunoglobulin E antibody (omalizumab) for the treatment of allergic respiratory disorders Am J Respir Crit Care Med 2001;164:S6-S11. https://doi. org/10.1164/ajrccm.164.supplement_1.2103025

46 Heusser C, Jardieu P. Therapeutic potential of anti-IgE antibodies. Curr Opin Immunol 1997;9:805-813. https://doi.org/10.1016/s09527915(97)80182-3

47 Jardieu P. Anti-IgE therapy. Curr Opin Immunol 1995; 7:779-82. https://doi.org/10.1016/0952-7915(95)80047-6

48 Prussin C, Griffith DT, Boesel KM, et al. Omalizumab treatment downregulates dendritic cell FcepsilonRI expression J Allergy Clin Immunol 2003;112:1147-1154. https://doi.org/10.1016/j.jaci.2003.10.003

49 Scheerens H, Smith A, Li O, et al. Elevated IgE M1 prime transcripts in nasal tissues in patients with nasal polyps and asthma. J Allergy Clin Immunol 2019;143:805-807. https://doi.org/10.1016/j. jaci.2018.10.011

50 Gevaert P, Omachi TA, Corren J, et al. Efficacy and safety of omalizumab in nasal polyposis: 2 randomized phase 3 trials. J Allergy Clin Immunol 2020;146:595-605. https://doi.org/10.1016/j. jaci.2020.05.032

51 Howarth P, Chupp G, Nelsen LM, et al. Severe eosinophilic asthma with nasal polyposis: a phenotype for improved sinonasal and asthma outcomes with mepolizumab therapy. J Allergy Clin Immunol 2020;145:1713-1715. https://doi.org/10.1016/j. jaci.2020.02.002

52 Chupp GL, Bradford ES, Albers FC, et al. Efficacy of mepolizumab add- on therapy on health-related quality of life and markers of asthma control in severe eosinophilic asthma (MUSCA): a randomised, double-blind, placebo-controlled, parallel-group, multicentre, phase 3b trial. Lancet Respir Med 2017;5:390-400. https://doi.org/10.1016/ S2213-2600(17)30125-X 
53 Ortega HG, Liu MC, Pavord ID, et al. Mepolizumab treatment in patients with severe eosinophilic asthma. N Engl J Med 2014;371:11981207. https://doi.org/10.1056/NEJMoa1403290

54 Han JK, Bachert C, Fokkens W, et al. Mepolizumab for chronic rhinosinusitis with nasal polyps (SYNAPSE): a randomised, double-blind, placebo-controlled, phase 3 trial. Lancet Respir Med 2021;S2213260000097. https//doi.org/10.1016/S2213-2600(21)00097-7

55 Hopkins C, Bachert C, Fokkens W, et al. Add-on mepolizumab for chronic rhinosinusitis with nasal polyps: SYNAPSE study. Eur Respir J 2020;56:4616. https://doi.org/10.1183/13993003

56 Kolbeck R, Kozhich A, Koike M, et al. MEDI-563, a humanized antiIL-5 receptor alpha $\mathrm{mAb}$ with enhanced antibody-dependent cell-mediated cytotoxicity function. J Allergy Clin Immunol 2010;125:13441353. https://doi.org/10.1016/j.jaci.2010.04.004

57 Bleecker ER, FitzGerald JM, Chanez P, et al. Efficacy and safety of benralizumab for patients with severe asthma uncontrolled with high-dosage inhaled corticosteroids and long-acting $\beta 2$-agonists (SIROCCO): a randomised, multicentre, placebo-controlled phase 3 trial. Lancet 2016;388:2115-2127. https://doi.org/10.1016/S01406736(16)31324-1

58 FitzGerald JM, Bleecker ER, Nair P, et al. Benralizumab, an antiinterleukin-5 receptor $\alpha$ monoclonal antibody, as addon treatment for patients with severe, uncontrolled, eosinophilic asthma (CALIMA): a randomised, double-blind, placebo-controlled phase 3 trial. Lancet 2016;388:2128-2141. https://doi.org/10.1016/S0140-6736(16)31322-8

59 Canonica GW, Harrison TW, Chanez P, et al. Benralizumab efficacy for severe, eosinophilic asthma with a diagnosis of nasal polyposis: results from the phase IIIb ANDHI trial. Abstracts from the European Academy of Allergy and Clinical Immunology Digital Congress, 0608 June 2020.

60 Bagnasco D, Brussino L, Bonavia M, et al. Efficacy of benralizumab in severe asthma in real life and focus on nasal polyposis. Respir Med 2020;171:106080. https://doi.org/10.1016/j.rmed.2020.106080

61 Tversky J, Lane AP, Azar A. Benralizumab effect on severe chronic rhinosinusitis with nasal polyps (CRSwNP): a randomized doubleblind placebo-controlled trial. Clin Exp Allergy 2021;51:836-844. https://doi.org/10.1111/cea.13852

62 Clinicaltrials.gov. Efficacy and safety study of benralizumab for patients with severe nasal polyposis (OSTRO). Available at: https:// clinicaltrials.gov/ct2/show/study/NCT03401229

63 Clinicaltrials.gov. Efficacy and safety study of benralizumab in patient with eosinophilic chronic rhinosinusitis with nasal polyps (ORCHID). Available at: https://clinicaltrials.gov/ct2/show/NCT04157335

64 Fokkens WJ, Lund V, Bachert C, et al. EUFOREA consensus on biologics for CRSwNP with or without asthma. Allergy 2019;74:23122319. https://doi.org/10.1111/all.13875

65 De Corso E, Kar M, Cantone E, et al. Facial pain: sinus or not? Acta Otorhinolaryngol Ital 2018;38:485-496. https://doi. org/10.14639/0392-100X-1721

66 Bourdin A, Adcock I, Berger P, et al. How can we minimise the use of regular oral corticosteroids in asthma? Eur Respir Rev 2020;29:190085. https://doi.org/10.1183/16000617.0085-2019

67 Hopkins C, Gillett S, Slack R, et al. Psychometric validity of the 22-item sinonasal outcome test. Clin Otolaryngol 2009;34:447-454. https://doi.org/10.1111/j.1749-4486.2009.01995.x

68 Rudmik L, Hopkins C, Peters A, et al. Patient-reported outcome measures for adult chronic rhinosinusitis: a systematic review and quality assessment. J Allergy Clin Immunol 2015;136:1532-1540.e2. https://doi.org/10.1016/j.jaci.2015.10.012

69 Lund VJ, Kennedy DW. Quantification for staging sinusitis. Ann Otol Rhinol Laryngol Suppl 1995;167:17-21. https://doi. org/10.1177/000348949510410s02
70 Meltzer EO, Hamilos DL, Hadley JA, et al. Rhinosinusitis: developing guidance for clinical trials. J Allergy Clin Immunol 2006;118:S17S61. https://doi.org/10.1016/j.jaci.2006.09.005

71 Hopkins C, Hettige R, Soni-Jaiswal A, et al. CHronic Rhinosinusitis Outcome Measures (CHROME), developing a core outcome set for trials of interventions in chronic rhinosinusitis. Rhinology 2018;56:22-32. https://10.4193/Rhin17.247

72 Joseph T, Auger SD, Peress L, et al. Screening performance of abbreviated versions of the UPSIT smell test. J Neurol 2019;266:18971906. https://doi.org/10.1007/s00415-019-09340-x

73 Hummel T, Sekinger B, Wolf SR, et al. 'Sniffin' sticks': olfactory performance assessed by the combined testing of odor identification, odor discrimination and olfactory threshold. Chem Senses 1997;22:39-52. https://doi.org/10.1093/chemse/22.1.39

74 Oleszkiewicz A, Schriever VA, Croy I, et al. Updated Sniffin' Sticks normative data based on an extended sample of 9139 subjects. Eur Arch Otorhinolaryngol 2019;276:719-728. https://doi.org/10.1007/ s00405-018-5248-1

75 Araújo-Martins J, Brás-Geraldes C, Neuparth N. The potential role of peak nasal inspiratory flow to evaluate active sinonasal inflammation and disease severity. Sci Rep 2020;10:12674. https://doi.org/10.1038/ s41598-020-69693-6

76 Li KL, Fang CH, Ferastraoaru D, et al. Patient satisfaction and efficiency benefits of a novel multidisciplinary rhinology and allergy clinic. Ann Otol Rhinol Laryngol 2020;129:699-706. https://doi. org/10.1177/0003489420905859

77 Canonica GW, Malvezzi L, Blasi F, et al. Chronic rhinosinusitis with nasal polyps impact in severe asthma patients: evidences from the Severe Asthma Network Italy (SANI) registry. Respir Med 2020;166:105947. https://doi.org/10.1016/j.rmed.2020.105947

78 Snidvongs K, Pratt E, Chin D, et al. Corticosteroid nasal irrigations after endoscopic sinus surgery in the management of chronic rhinosinusitis. Int Forum Allergy Rhinol 2012;2:415-421. https://doi. org/10.1002/alr.21047

79 Snidvongs K, Kalish L, Sacks R, et al. Sinus surgery and delivery method influence the effectiveness of topical corticosteroids for chronic rhinosinusitis: systematic review and meta-analysis. Am J Rhinol Allergy 2013;27:221-233. https://doi.org/10.2500/ajra.2013.27.3880

80 Nakayama T, Asaka D, Kanaya H, et al. Prognostic factors for recurrence after endoscopic sinus surgery for chronic rhinosinusitis with nasal polyps. Auris Nasus Larynx 2016;43:641-647. https://doi. org/10.1016/j.anl.2016.02.015

81 Wu CL, Lee TJ, Huang CC, et al. Clinical predictors of revision surgery for chronic rhinosinusitis with nasal polyposis within 5-year follow-up. Am J Otolaryngol 2020;41:102654. https://doi.org/10.1016/j. amjoto.2020.102654

82 Amedee RG. Prevalence of polyp recurrence after endoscopic sinus surgery for chronic rhinosinusitis with nasal polyposis. Am J Rhinol Allergy 2017;31:278. https://doi.org/10.2500/194589217821335822

83 Alsharif S, Jonstam K, van Zele T, et al. Endoscopic sinus surgery for type-2 CRS wNP: an endotype-based retrospective study. Laryngoscope 2019;129:1286-1292. https://doi.org/10.1002/lary.27815

84 Hopkins C, Lund V. Does time from previous surgery predict subsequent treatment failure in chronic rhinosinusitis with nasal polyps? Rhinology 2021;59:277-283. https://doi.org/10.4193/Rhin21.017

85 Bhattacharyya N, Villeneuve S, Joish VN, et al. Cost burden and resource utilization in patients with chronic rhinosinusitis and nasal polyps. Laryngoscope 2019;129:1969-1975. http://doi.org/10.1002/ lary.27852

86 Roland LT, Smith TL, Schlosser RJ, et al. Guidance for contemporary use of biologics in management of chronic rhinosinusitis with nasal polyps: discussion from a National Institutes of Health-sponsored 
workshop. Int Forum Allergy Rhinol 2020;10:1037-1042. https://doi. org/10.1002/alr.22633

${ }^{87}$ Gurrola J II, Borish L. Chronic rhinosinusitis: endotypes, biomarkers, and treatment response. J Allergy Clin Immunol 2017;140:14991508. https://doi.org/10.1016/j.jaci.2017.10.006

88 Brown WC, Senior B. A critical look at the efficacy and costs of biologic therapy for chronic rhinosinusitis with nasal polyposis. Curr Allergy Asthma Rep 2020;20:16. https://doi.org/10.1007/s11882-020-00910-y

89 Anderson WC, Szefler SJ. Cost-effectiveness and comparative effectiveness of biologic therapy for asthma: to biologic or not to biologic? Ann Allergy Asthma Immunol 2019;122:367-372. https://doi. org/10.1016/j.anai.2019.01.018

90 Whittington MD, McQueen RB, Ollendorf DA, et al. Assessing the value of mepolizumab for severe eosinophilic asthma: a cost-effectiveness analysis. Ann Allergy Asthma Immunol 2017;118:220-225. https://doi.org/10.1016/j.anai.2016.10.028

91 Lam J, Hay JW, Salcedo J, et al. A cost-effectiveness analysis of reslizumab in the treatment of poorly controlled eosinophilic asthma. J Asthma 2019;56:872-881. https://doi.org/10.1080/02770903.2018.1500584

92 Tice JA, Campbell JD, Synnott PG, et al. The effectiveness and value of biologic therapies for the treatment of uncontrolled asthma. $J$ Manag Care Spec Pharm 2019;25:510-514. https//doi.org/10.18553/ jmcp.2019.25.5.510
93 Blackwell DL, Collins JG, Coles R. Summary health statistics for U.S. adults: National Health Interview Survey, 1997. Vital Health Stat 2002;10:1-109.

94 Rudmik L, Soler ZM, Smith TL, et al. Effect of continued medical therapy on productivity costs for refractory chronic rhinosinusitis. JAMA Otolaryngol Head Neck Surg 2015;141:969-973. https://doi. org/10.1001/jamaoto.2015.2321

95 Rudmik L, Smith TL, Mace JC, et al. Productivity costs decrease after endoscopic sinus surgery for refractory chronic rhinosinusitis. Laryngoscope 2016;126:570-574. https://doi.org/10.1002/ lary. 25656

96 Luk LJ, Steele TO, Mace JC, et al. Health utility outcomes in patients undergoing medical management for chronic rhinosinusitis: a prospective multiinstitutional study. Int Forum Allergy Rhinol 2015;5:1018-1027. https://doi.org/10.1002/alr.21588

97 Beswick DM, Mace JC, Rudmik L, et al. Productivity changes following medical and surgical treatment of chronic rhinosinusitis by symptom domain. Int Forum Allergy Rhinol 2018;8:1395-1405. https://doi. org/10.1002/alr.22191

98 Chowdhury NI, Mace JC, Smith TL, et al. What drives productivity loss in chronic rhinosinusitis? A SNOT-22 subdomain analysis. Laryngoscope 2018;128:23-30. https://doi.org/10.1002/lary.26723 